Revista de Derecho

\title{
La reparación inmaterial y el arte frente a violaciones de derechos humanos. Análisis del caso Barrios Altos vs. Perú
}

\author{
Intangible reparation and the art \\ of facing violations of Human Right. \\ Analysis of the Barrios Altos vs. Peru case
}

\author{
Adrián Alejandro Alvaracín Jarrín \\ Coordinador de indultos presidenciales \\ de la Subdirección de Rehabilitación Social del SNAI, Ecuador \\ adrian_alvaracin.j@hotmail.com. \\ ORCID: https://orcid.org/0000-0002-0740-1152
}

DOI: https://doi.org/10.32719/26312484.2020.33.7

Fecha de recepción: 26 de agosto de 2019

Fecha de aceptación: 16 de septiembre de 2019 


\section{RESUMEN}

La tarea investigativa emprendida en este trabajo evalúa mediante estándares doctrinales la reparación inmaterial dictada por la Corte Interamericana de Derechos Humanos en la sentencia emblemática del caso Barrios Altos vs. Perú, a fin de analizar en la ratio decidendi si la actuación de la Corte Interamericana de Derechos Humanos se ajusta a una visión integral sobre reparación simbólica. El presente trabajo se justifica en la manera en que las víctimas aparecen como actores secundarios en la realización de las obras de arte como objeto de reparación inmaterial, ante lo cual se busca la forma de que las mismas sean sujetos protagonistas, considerando relevante su intervención al momento de establecer la forma y fondo de las manifestaciones artísticas como objeto de su reparación. Como metodología se aplica el estudio de caso, mismo que permite a través del análisis de la sentencia expuesta, formular propuestas amplias y generales en cuanto a la reparación simbólica. Como resultado, se interconecta el arte con el derecho y se propone una reparación inmaterial respetuosa de las vivencias, experiencias y reclamos de las víctimas de violaciones a los derechos humanos. En las conclusiones se señala las falencias de la Corte Interamericana de Derechos Humanos al momento de aplicar estándares doctrinales que permitan una reparación inmaterial basada en una dialéctica entre decisión judicial, víctimas, artistas y el Estado, con el propósito de fomentar conciencia y encaminar una reparación transformadora de la realidad.

PALABRAS CLAVE: arte, derecho, derechos humanos, justicia restaurativa, reparación inmaterial, víctimas.

\section{ABSTRACT}

The investigative task undertaken in this work evaluates by means of doctrinal standards the immaterial reparation issued by the Inter-American Court of Human Rights in the emblematic judgment of the Barrios Altos vs.. Peru case, in order to analyze in the ratio decidendi, if the action of the Inter American Court of Human Rights conforms to a comprehensive vision on symbolic repair. This research is justified based in the way victims appear as secondary actors in the development of works of art as an object of immaterial reparation; therefore, the way in which they are the main subjects is sought, considering their intervention relevant when establishing the form and substance of the artistic manifestations as the object of their repair. As a methodology, a case study is applied, which allows through the analysis of the sentence set forth, to formulate broad and general proposals regarding symbolic reparation. As a result, art is interconnected with the law and immaterial reparation is proposed that respects the experiences and claims of victims of violations of human rights. The conclusions indicate the shortcomings of the Inter-American Court of Human Rights when applying doctrinal standards that allow immaterial reparation based on dialectic between judicial decision, victims, artists and the state, with the purpose of raising awareness and directing a reparation reality transformer.

KeYwORDs: Art, Law, Human Rights, Restorative Justice, Immaterial Reparation, Victims. 


\section{INTRODUCCIÓN}

$\mathrm{E}$ 1 objetivo principal de este trabajo radica en encontrar una forma adecuada de reparación inmaterial para las víctimas de violaciones a los derechos humanos, que gira en torno a cuatro aspectos importantes que son: la participación de las víctimas; el equilibrio entre los elementos éticos y estéticos, el arte accesible y por último, el manejo, mantenimiento y conservación. Esos cuatro aspectos se analizan en la sentencia hito de la Corte Interamericana de Derechos Humanos en el caso Barrios Altos vs. Perú, ${ }^{1}$ verificando si se cumplen en la misma, además de analizar si son necesarios para una reparación simbólica eficaz.

De modo que se utiliza la estrategia metodológica de estudio de caso, la cual permite usar el método inductivo como herramienta para analizar la sentencia de la Corte Interamericana de Derechos Humanos (Corte IDH) en particular y a partir de allí, luego de un análisis a profundidad, generar regularidades aplicables a casos semejantes, pues como señala Villabela:

El proceso de inducción recorre el camino de lo particular a lo general, ya que a partir de situaciones específicas induce regularidades válidas o aplicables a casos semejantes, obviando lo relativo o cambiante, y buscando las formas estables. Esta es la manera de establecer conclusiones desde el estudio de casos y la forma de razonar en las investigaciones cualitativas. $^{2}$

A su vez, como señala Guglielmucci, las víctimas desde el derecho comprenden una "significación [que] permite dar cuenta del modo en que el sufrimiento es reconocido y empleado como un recurso para demandar a las instituciones estatales y a diversos organismos internacionales (como la Comisión Interamericana de Derechos Humanos) y acceder a ciertos derechos vinculados a la reparación del daño (...)", ${ }^{3}$ lo que se traduce en que la reparación a las víctimas debe elevar su voz como parte de su reconocimiento, por lo cual se verificará si la sentencia Barrios Altos vs. Perú cumple con entregar un rol protagónico a las víctimas en la creación de las manifestaciones artísticas como parte de su reparación inmaterial.

1. Corte Interamericana de Derechos Humanos, "Sentencia de fondo", Caso Barrios Altos vs. Perú, 14 de marzo de 2001.

2. Carlos Manuel Villabella, "Los métodos en la investigación jurídica. Algunas precisiones", en Metodologías: enseñanza e investigación jurídica, ed. Wendy Aide Godínez Méndez y José Heriberto García Peña (Ciudad de México: UNAM / Tecnológico de Monterrey, 2015), 938, «https://archivos.juridicas.unam.mx/ www/bjv/libros/8/3983/46.pdf〉.

3. Ana Guglielmucci, "El concepto de víctima en el campo de los derechos humanos: una reflexión crítica a partir de su aplicación en Argentina y Colombia", Revista de Estudios Sociales, n. ${ }^{\circ} 59$ (2017): 87, 〈http:// www.redalyc.org/pdf/815/81549422008.pdf . 
La pregunta que guía el análisis de la sentencia del caso Barrios Altos vs. Perú, es la siguiente: ¿la decisión de la Corte IDH en materia de reparación cumple con los estándares de una reparación inmaterial efectiva en casos de violaciones a los derechos humanos?

Bajo esa pregunta, el análisis de caso gira en torno a la reparación inmaterial efectuada por la Corte IDH en relación con la protección eficaz y simbólica a través de la manifestación del arte llevada a cabo en el monumento El ojo que llora ubicado en Lima-Perú, así como la conservación de la memoria histórica y la transformación de conciencias en la sociedad, entregando aportes para una innovadora reparación simbólica, proyectando una reparación inmaterial que tienda a modificar las condiciones de vulnerabilidad que permiten la violación a los derechos humanos de inmensas mayorías de la población.

En consecuencia, se interconecta el arte con el derecho, ambos desde un enfoque trasformador. La obra de arte contiene dos polos que se traducen en su valor ritual y en su valor de exhibición, mientras que el primero implica la magia artística, el ocultamiento, el culto y la activa participación del hombre, ofreciendo imágenes de su entorno, el segundo se centra en cambio en la máquina, despojando al hombre su participación. ${ }^{4}$ Entonces, es el valor ritual del arte el que puede ser usado desde el derecho, con activa participación de las víctimas, los artistas y el Estado.

Es preciso indicar que en el trayecto del análisis se advierten las complicaciones que trae una reparación inmaterial con contenido artístico que no se adecue a la participación activa de las víctimas y a la responsabilidad del Estado en cumplir sus obligaciones internacionales. El memorial El ojo que llora ha sido un espacio donde convergen distintas opiniones y críticas, que se reflejan en atentados, protestas y opiniones en torno a la obra de arte; por ello es necesario ampliar las condiciones que una manifestación artística debe contener para evitar la afectación a la memoria de las víctimas y entregar al arte un uso transformador.

En este sentido, el arte tiene una finalidad comunicativa capaz de calar en las emociones humanas. La pintura, la escultura, la música, el teatro o cualquier otra manifestación artística, es capaz de expresar ideas y el sentir; aquella como instrumento del derecho puede servir enormemente para reparar a las víctimas de violaciones de derechos humanos. En el arte se deposita el dolor y la valentía de las víctimas, así como la resistencia o la protesta; se da forma a un trabajo emotivo que recordará una y otra vez al conjunto social que los hechos por los que se creó, no se pueden volver

4. Walter Benjamin, La obra de arte en su reproductibilidad técnica (Ciudad de México: Ítaca, 2003), 52-7. 
a repetir. Esta función del arte es trascendental, por la inmortalización de la memoria histórica, convirtiéndose en reparación que no se agota.

\section{ARGUMENTO}

Es conocido por la experiencia histórica de nuestros pueblos que sufrieron las dictaduras sangrientas en la década de los 70, que por omisiones en la conciencia se vean obligados a repetir los hechos que afectaron a la sociedad en su conjunto. Desapariciones, torturas y otras graves violaciones a los derechos humanos han sido una constante en nuestra región. Por estas razones, la sentencia emblemática escogida para el análisis resuena en los umbrales del terrorismo de Estado, cuyo caso se denomina Barrios Altos vs. Perú.

Dicha sentencia trata sobre la condena y reparación de los hechos acontecidos en 1991 en Barrios Altos en Lima, lugar donde fueron asesinadas quince personas y cuatro quedaron gravemente heridas, esto como resultado de la operación del escuadrón de eliminación denominado Grupo Colina, ${ }^{5}$ compuesto por miembros del ejército peruano, quienes bajo el pretexto de combatir grupos guerrilleros, irrumpieron en una fiesta en el sector Barrios Altos, disparando a los presentes por más de dos minutos. Posteriormente, el Congreso peruano promulgó leyes de amnistía ${ }^{6}$ para aquellos que hubieran intervenido en estos y otros hechos durante el período 1980-1995, impidiendo que se investiguen. La Corte IDH condenó al Estado por violaciones a los derechos establecidos en la Convención, disponiendo que se erija un monumento en honor a las víctimas.

Es así que en la sentencia de fondo se establece por primera vez la incompatibilidad de las disposiciones de amnistía que impiden la investigación y reparación de las víctimas por violaciones a los derechos humanos, señalando que: "Las leyes de autoamnistía conducen a la indefensión de las víctimas y a la perpetuación de la impunidad, por lo que son manifiestamente incompatibles con la letra y el espíritu de la Convención Americana", 7 determinando que las autoamnistías emanadas por altas autoridades del gobierno son incompatibles con el derecho al acceso a la justicia y el derecho a la verdad, interfiriendo en gran medida sobre la reparación de las víctimas.

De la misma forma es la sentencia hito en cuanto a reparación a las víctimas al establecer por primera vez la reparación inmaterial a través del arte, pues en la deci-

5. Corte Interamericana de Derechos Humanos, "Sentencia de fondo", párr. 3.

6. Ibíd., párr. 15 .

7. Ibíd. 
sión de la sentencia de fondo se dispone que: "las reparaciones serán fijadas de común acuerdo por el Estado demandado, la Comisión Interamericana y las víctimas, sus familiares o sus representantes legales debidamente acreditados, dentro de un plazo de tres meses contados a partir de la notificación de la presente Sentencia", ${ }^{8}$ para luego en la sentencia sobre reparaciones y costas del 30 de noviembre de 2001 establecer lo siguiente: "erigir un monumento recordatorio. El lugar será acordado entre las partes en coordinación con la Municipalidad Metropolitana de Lima, y el 'monumento será instalado dentro de los 60 días de suscrito el acuerdo" ". ${ }^{9}$

Se debe agregar que en este caso el Estado incumplió lo ordenado por la Corte IDH, existiendo la resolución sobre supervisión de sentencia del año $2012^{10}$ y asimismo otra supervisión de sentencia en el año 2018 en las cuales se determina el incumplimiento mencionado, esto es, construir un monumento que resguarde la memoria de las víctimas ${ }^{11}$ y que sea un espacio de reflexión para la sociedad en general.

Ante este incumplimiento, por iniciativa privada, la escultora de origen holandés Lika Mutal conjuntamente con los afectados, lograron erigir dicho monumento como memorial a las víctimas de los horrendos crímenes cometidos por el Estado en tiempos de Fujimori y Montesinos. Construido en el Campo de Marte, un parque que se ubica en el distrito de Jesús María en Lima-Perú, dicho memorial recibió el nombre de El ojo que llora, que describe de manera colosal el sentimiento inconcluso y aberrante que siente la Madre Tierra o Pachamama por la violencia desplegada por sus propios hijos; ella llora de profundo dolor por los actos terroríficos a los que somete un poder punitivo descontrolado y dirigido a aniquilar la vida en el planeta.

Aquí vemos la importancia de artistas comprometidos con la causa, pues Lika Mutal luego de acudir a una exposición fotográfica en Lima denominada Yuyanapaq la cual demostraba los años de violencia política desencadenada por Sendero Luminoso y perpetrada a gran escala por el Estado, observó que se ejecutaron a personas de los estratos más pobres y excluidos de la sociedad, como resultado desaparecieron cerca de 70.000 peruanos; ${ }^{12}$ en ese contexto Lika Mutal decidió crear El ojo que llora como expresión artística de lucha y de memoria, conjuntamente con las víctimas de los años del terror.

8. Ibíd., 18.

9. Corte Interamericana de Derechos Humanos, "Sentencia de reparaciones y costas", Caso Barrios Altos vs. Perú, 30 de noviembre de 2001.

10. Corte Interamericana de Derechos Humanos, "Resolución de supervisión de cumplimiento", Caso Barrios Altos vs. Perú, 7 de septiembre de 2012.

11. Corte Interamericana de Derechos Humanos, "Resolución de supervisión de cumplimiento", Caso Barrios Altos y Caso la Cantuta vs. Perú, 30 de mayo de 2018.

12. Mario Vargas Llosa, "El ojo que llora", El Pais, 2019, 〈https://elpais.com/diario/2007/01/14/opinion/ 1168729205_850215.html). 
Además, El ojo que llora es un monumento que consta de una piedra central con el diseño de un ojo en la parte superior de donde brota agua que representan las lágrimas, con su laberinto de cantos rodados en donde se halla la inscripción de los nombres de las víctimas del conflicto armado interno, el cual invita a la reflexión, a la crítica y a la conciliación entre hermanos que cohabitan el mismo espacio sagrado de la Madre Tierra. Es una creación artística que honra y cobija la memoria de los deudos y las víctimas, de los desposeídos y de los muertos, que encamina su escultura hacia la conciencia de las mujeres y hombres para que los actos que derramaron tanta sangre, no invadan nuevamente la paz social. Para efectos de comprensión, se reproduce una imagen del memorial.

\section{Imagen 1. El ojo que llora}

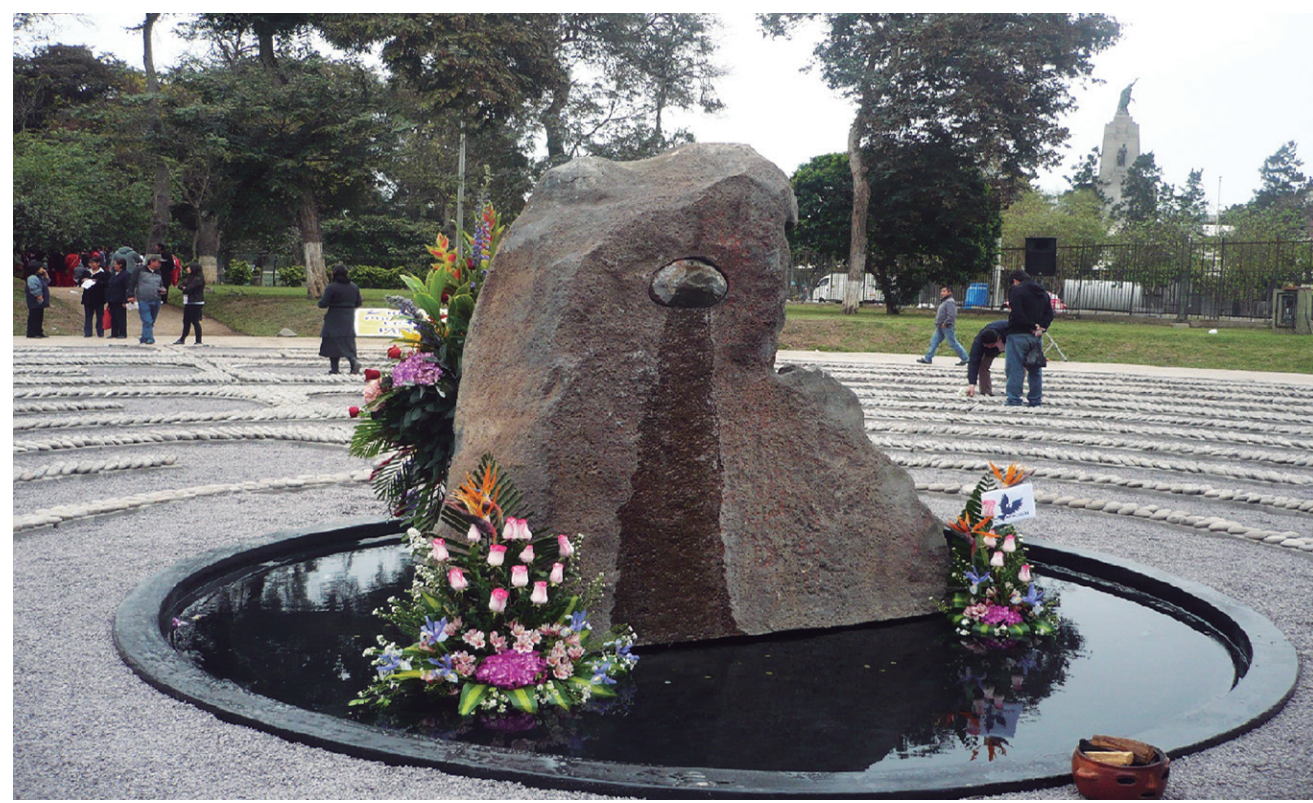

Fuente: Christian Reynoso. ${ }^{13}$

Elaboración: Lika Mutal, 28 de agosto de 2005.

13. Christian Reynoso, "Foto en entrada de blog 'No olvidar para poder construir memoria y derechos humanos" ", UTexas, accedido 20 de septiembre de 2019, «https://sites.utexas.edu/llilas-benson-blog/2014/ 03/26/no-olvidar-para-poder-construir-memoria-y-derechos-humanos/>. 
Volviendo al análisis, la Corte IDH avanzó sobre este precedente mediante una segunda interpretación progresiva de los derechos y sobre todo del derecho a la reparación inmaterial, al valorar en la sentencia de fondo del caso La Cantuta vs. Perú, en el cual los deudos de diez víctimas demandaron ante la Comisión Interamericana de Derechos Humanos, el asesinato de varios estudiantes y un profesor, durante el conflicto generado por el combate al terrorismo, disponiendo su inclusión en el monumento El ojo que llora, de esta manera:

la existencia del monumento y sitio público denominado "El ojo que llora", creado a instancias de la sociedad civil y con la colaboración de autoridades estatales, lo cual constituye un importante reconocimiento público a las víctimas de la violencia en el Perú. Sin embargo, el Tribunal considera que el Estado debe asegurarse que, dentro del plazo de un año, las 10 personas declaradas como víctimas ejecutadas o de desaparición forzada en la presente Sentencia se encuentren representadas en dicho monumento, en caso de que no lo estén ya y si sus familiares así lo desean. Para ello, deberá coordinar con los familiares de las víctimas la realización de un acto, en el cual puedan incorporar una inscripción con el nombre de la víctima, según la forma que corresponda de acuerdo con las características del monumento". ${ }^{14}$

El ojo que llora también ha sido un espacio de lucha, convirtiéndose en motivo de debate y polémica, desencadenado por la reparación simbólica ordenada por la Corte IDH en el caso Penal Miguel Castro Castro vs. Perú. Dicho caso trata sobre las víctimas que se encontraban en el establecimiento carcelario penal Miguel Castro Castro en 1992, acusadas de terrorismo y de pertenecer a Sendero Luminoso, el cual había desencadenado el conflicto interno armado en el país. Cuando el presidente Fujimori asumió poderes dictatoriales en el año de 1992, implementó prácticas violatorias de los derechos humanos para combatir la subversión, ordenando el Operativo Mudanza $1,{ }^{15} \mathrm{el}$ cual atentó mediante fuerzas policiales y militares, quienes portaban armamento bélico, contra la vida de los internos e internas del penal. Como resultado de ese operativo fallecieron cuarenta y un personas que pertenecían al grupo Sendero Luminoso. ${ }^{16}$

Cabe resaltar que el Estado reconoció parcialmente su responsabilidad por la muerte de dichas personas en la masacre ocurrida en el penal Castro Castro, pero se negó a reparar a las víctimas con una placa en dicho establecimiento penal, aducien-

14. Corte Interamericana de Derechos Humanos, "Sentencia de fondo, reparaciones y costas", Caso La Cantuta vs. Perú, 29 de noviembre de 2006.

15. Corte Interamericana de Derechos Humanos, "Sentencia de fondo, reparaciones y costas", Caso del Penal Miguel Castro Castro vs. Perú, 25 de noviembre de 2006.

16. Ibíd., 76-80. 
do que existe un monumento que conmemora a todas las víctimas de ese conflicto interno. Pese a la solicitud de la Comisión Interamericana de Derechos Humanos que recomienda como reparación a las víctimas erigir un monumento o destinar un lugar en memoria de las víctimas de esa masacre, ${ }^{17}$ la Corte IDH fijó como reparación simbólica la siguiente:

El Estado debe asegurar, dentro del plazo de un año, que todas las personas declaradas como víctimas fallecidas en la presente Sentencia se encuentren representadas en el monumento denominado 'El Ojo que Llora', para lo cual debe coordinar con los familiares de las referidas víctimas la realización de un acto, en el cual puedan incorporar una inscripción con el nombre de la víctima como corresponda conforme a las características de dicho monumento, en los términos de los párrafos 454 y 463 de la presente Sentencia". ${ }^{18}$

La problemática de esta decisión persiste hasta la actualidad polarizando a la sociedad peruana, la cual delibera sobre si los nombres de aquellos internos masacrados que pertenecían al grupo Sendero Luminoso deben escribirse junto a los nombres de las víctimas civiles del conflicto interno generado por ese grupo y el Estado. La opinión opositora declara que dicha resolución singulariza como víctimas a los terroristas y relega a los soldados y miembros policiales victimados por Sendero Luminoso. ${ }^{19}$ A este problema se suman otras protestas, como la acontecida en 2007 donde un grupo armado destruyó parte de la escultura y la pintó de color naranja por considerarlo un monumento al terrorismo. Con estos acontecimientos se puede vislumbrar que la reparación inmaterial que incorpore obras de arte debe construirse con todos los actores perjudicados, para evitar confrontaciones.

Como se analiza, la Corte IDH encontró en El ojo que llora el espacio artístico para plasmar la reparación inmaterial, buscando las vías posibles para conquistar la conciencia y deshacer del imaginario social la idea de que el Estado tiene derecho a ejercer la fuerza y la violencia sobre su población. Obviamente esta expresión simbólica va más allá de la idea de una restitución del daño producido, pues esta no busca devolver las cosas al estado anterior en que se encontraba la víctima o el bien jurídico protegido, sino que busca reconstruir la conciencia colectiva, encaminada a transformar la realidad. Por ello, su importancia se desprende de las víctimas como tal y trasciende a la sociedad, siendo un instrumento de valoración, conciencia, reflexión y autocrítica para toda la población y de juzgamiento al Estado que viola sistemáticamente los derechos humanos.

17. Ibíd., 133.

18. Ibíd., 154.

19. Vargas Llosa, "El ojo que llora". 
Hay que mencionar que la sentencia Barrios Altos vs. Perú fundó una línea jurisprudencial sobre reparación inmaterial. Para López Medina la línea jurisprudencial solo es posible si el intérprete construye una teoría jurídica integral a través de la narración, para lo cual interrelaciona diversos pronunciamientos relevantes en cuanto a la materia que se desea interpretar; es así que establece tres exigencias para el establecimiento de una línea jurisprudencial: “(i) acotar el patrón fáctico concreto [...] (ii) identificar las sentencias más relevantes; (iii) construir teorías estructurales que permitan establecer la relación entre esos varios pronunciamientos jurisprudenciales". ${ }^{20}$

En cuanto al primer punto se refiere al escenario relevante en el que la Corte IDH ha establecido la reparación inmaterial, fijando como patrón fáctico el derecho a la vida y el derecho a la integridad personal. Respecto del segundo punto, se ha identificado a la sentencia Barrios Altos vs. Perú como una sentencia hito que ha permitido desarrollar argumentaciones para reparar integralmente y de manera simbólica a las víctimas de violaciones a los derechos humanos, a través del arte. El tercer y último punto se verifica cuando la Corte IDH emite varios pronunciamientos en los que incluye el arte como reparación inmaterial, como sucedió en los casos Barrios Altos, La Cantuta y Penal Castro Castro. De esta forma, la reparación inmaterial como precedente se ha vuelto posible gracias al arte, específicamente plasmada en El ojo que llora, como expresión de denuncia, reclamo, reconciliación y pacificación.

A pesar de que la línea jurisprudencial de la Corte IDH encamina una propuesta de reparación inmaterial, es necesario saber si la misma cumple con los estándares para convertirse en una herramienta de transformación. Así para Sierra León, las obras con contenido de derechos humanos deben coadyuvar al proceso de transformación y emancipación, algo así como el uso político del arte, debiendo para ello cumplir cuatro supuestos:

1. Que la obra de arte haya sido precedida por un proceso estatal, sea judicial o administrativo, donde se hayan determinado los responsables del daño o el perjuicio a la víctima. 2. Que haya sido ordenada por un juez o por una autoridad competente como un mecanismo expreso de reparación integral o de reparación simbólica. 3. Que la concepción y ejecución de la obra haya sido el resultado de un proceso creativo conjunto entre el artista y las víctimas, y no solamente del artista. 4. Que la financiación y responsabilidad de la ejecución de la obra esté a cargo del responsable del daño o el perjuicio. 5. Que la obra haya tenido en cuenta el contexto sociocultural de la víctima. ${ }^{21}$

20. Diego Eduardo López Medina, El derecho de los jueces (Bogotá: Legis Editores, 2008), 140.

21. Yolanda Sierra León, "Relaciones entre el arte y los derechos humanos", Revista Derecho del Estado, n. ${ }^{\circ}$ 32 (2014): 94, 〈https://revistas.uexternado.edu.co/index.php/derest/article/view/3815〉. 
De la sentencia analizada se desprende que los supuestos mencionados se cumplieron en gran medida, considerando que el Estado peruano se ha negado a construir el monumento cuyo objetivo es la sensibilización del imaginario colectivo en torno a las violaciones de derechos humanos. Sin embargo, estos supuestos son necesarios para que la reparación inmaterial pueda tener efectos transformadores y no meramente simbólicos.

El Estado condenado, cuando cumple sus obligaciones en materia internacional de protección a los derechos humanos, produce los siguientes efectos:

el fin del Estado es reparar a las víctimas y contribuir con la garantía de no repetición; mientras que el fin de los artistas es manifestar su sensibilidad en relación con un tema específico que les interesa abordar; y para las víctimas, son mecanismos de resistencia y denuncia que permiten pasar del trauma individual a la conformación de sujetos colectivos con capacidad para incidir en las condiciones sociales que generan la violación a sus derechos humanos..$^{22}$

El arte configura su potencial emancipador cuando alerta a los sentidos de la persona, es así que para Ronald Barthes: "el sentido del tacto es el más desmitificador de los sentidos, al contrario de la vista, que es el más mágico" ${ }^{23}$ lo cual se verifica en el memorial El ojo que llora, pues el mismo contribuye a que el observador se sumerja en la obra de arte, la contemple en su totalidad, se genere en la persona una mixtura de fraternidad y de aberración. Es a través del ojo que la persona llega a la contemplación. Por esta razón, la construcción de memoriales permite calar en lo profundo de un auditorio que desconoce su realidad histórica y que necesita rememorar esos hechos aterradores para no caer en la trampa siempre constante de concebir al poder punitivo como una manera de solucionar conflictos.

Es así que las obras de arte facilitan al derecho plasmar sus finalidades en la realidad, pues la obra denuncia las experiencias de quienes sufren y las injusticias de un Estado indolente y allí en esa realidad de la obra de arte, encontramos el posible sentido de transformación que pretende el derecho. Sin esas obras, el derecho penal no actúa, pues se encierra en la mentalidad punitiva del castigo y en la confiscación del protagonismo de las víctimas. Por ello, la posibilidad de romper el esquema punitivo y la indolencia hacia las víctimas, la encontramos en el arte como espacio de lucha y de transformación hacia una justicia comprometida con entregar voz a quienes fueron acallados por un Estado terrorista.

22. Ibíd., 77.

23. Ronald Barthes, Mitologías (Buenos Aires: Siglo XXI, 2008), 156. 
La configuración de esa realidad a través de las obras de arte se verifica cuando la misma cumple estándares que logran entregar una reparación inmaterial como reparación de la memoria. Para Lina Parra existen presupuestos para evaluar que la reparación simbólica establecida en una sentencia pueda considerarse eficaz, los cuales se resumen así: "1. Participación de las víctimas al determinar la forma de reparación, en consecuencia, no homogeneización, ni estandarización. 2. Equilibrio entre los elementos éticos y estéticos, y participación de las víctimas en el proceso de creación de la obra. 3. Arte accesible. 4. Manejo, mantenimiento y conservación" ${ }^{24}$ Bajo estos presupuestos, la Corte IDH respetó parcialmente los numerales 1 y 2 , mientras que los numerales 3 y 4 no se cumplirían. Este abordaje, cabe explicar, se lo realiza con el fin de optimizar lo dispuesto por la Corte IDH en materia de reparación integral, es decir, que sirva para una mejor decisión respecto de las reparaciones en casos de violaciones a los derechos humanos.

Entonces, tenemos que el numeral 1 se vincula a la dignidad de las personas, pues devolver el protagonismo a la víctima significa escuchar sus reclamos, dolencias e interrogantes, que permitan ajustar conforme a la verdad de los hechos, el deseo de la misma sobre su reparación; actuar de manera contraria significa desperdiciar la oportunidad de reparar el daño ocasionado y de fomentar verdadera conciencia en el escenario social. El construir un monumento sin determinar previamente las características y la esencia de la obra de arte que se pretende plasmar, simplemente evoca una proyección inconclusa que luego impide reparar a la víctima. En la sentencia de Barrios Altos vs. Perú se puede encontrar esa displicencia por parte de la Corte IDH respecto de la determinación concreta del monumento que dispone se construya, lo cual a la postre puede causar inconvenientes para las víctimas y para el Estado.

Respecto del numeral 2, la Corte IDH inobservó las formas éticas y estéticas del monumento que ordenó construir, pues paradójicamente la obra debe guardar en su estructura dos momentos: la memoria y el olvido. Esto es posible a través del tiempo y el espacio; por un lado el tiempo conmemora y desmemoria a las personas, mientras que el espacio penetra en la mente del observador y lo conduce a reflexionar sobre lo que observa. El espacio debe ser comunitario, reflejando el principio de solidaridad, el cual "es un valor fundamental que refuerza el 'mundo de la vida', la creación de un espacio público favorable a la deliberación y exige 'la apertura del nosotros a personas a las que anteriormente hemos considerado ellos " ${ }^{25}$ Lo ético logra que la obra

24. Lina Victoria Parra Cortés, "Relaciones entre el arte y el derecho: ejemplos del arte en los procesos de protesta, memoria y reparación", Anamorphosis-Revista Internacional de Direito e Literatura 5 , n. ${ }^{\circ} 1$ (2019): 245, 〈http://seer.rdl.org.br/index.php/anamps/article/view/468/pdf〉.

25. Ramiro Ávila Santamaría, La utopía del oprimido. Los derechos de la pachamama (naturaleza) y el sumak kawsay (buen vivir) en el pensamiento crítico, el derecho y la literatura (Ciudad de México: Akal, 2019$), 318$. 
rememore a los hechos y a las víctimas; lo estético determina cómo y de qué manera la obra de arte establecerá el impacto deseado en las víctimas y la sociedad.

Los numerales 3 y 4 se refieren por un lado a la accesibilidad a la obra conmemorativa, conlleva un aspecto económico que permita el acceso de innumerables personas, pues se trata de delitos imprescriptibles que dejan huella indeleble en el transitar histórico de la sociedad. El numeral 4 implica el cuidado y mantenimiento que debe darse a la obra, pues como se señaló anteriormente las obras de arte que son fundamento de la reparación integral tienen un valor ritual el cual cumple la función de reactivar la memoria sobre los hechos ocurridos y de fomentar conciencia. Este último aspecto no ha sido tomado en cuenta por la Corte IDH ${ }^{26}$ pese a su importancia como garantía frente a hechos vandálicos o partidistas.

En todos estos aspectos señalados se concibe a la víctima con su rol protagónico, eso conduce a la sociedad hacia una justicia restaurativa. El escuchar a las víctimas es necesario para una reparación inmaterial acorde a estándares efectivos que posibiliten dotar a las decisiones judiciales de instrumentos que evalúen y midan la reparación. Es necesario entender que el derecho debe pensarse desde "las personas, colectivos y naturaleza, que están al margen del poder estatal o económico, debería ser la base cuando se piensa que la soberanía está en el pueblo", ${ }^{27}$ es por ello que cualquier reparación simbólica debe tomar como eje los cuestionamientos de las víctimas y sus deudos.

Lo señalado es lo que se conoce como la prueba de lo indecible del derecho, que consiste en despreciar la voz de quienes sufren las injusticias al no considerarse fuente ni doctrina, pues las mismas no corresponden a la teoría elitista del derecho. En cambio, desde una perspectiva popular y tomando en serio los derechos, Ramiro Ávila sostiene que "si se pasa la prueba de lo indecible, es decir si se permite la voz propia, y esta es escuchada y tiene relevancia jurídica, entonces hay justicia". ${ }^{28}$

La marginalidad de las voces de las víctimas provoca una violencia desde el derecho, al impedirles expresar sus dolencias y sus deseos. Desmitificar esa marginalidad es tarea que se emprende desde el arte, pues otorga voz a las víctimas, las envuelve en su belleza y las poetiza en sus esculturas; también sirve como demanda al elevar en sus diseños los reclamos y la memoria de su sufrimiento. Por ello el arte es "un medio de resistencia, de denuncia y de lucha, y al mismo tiempo un mecanismo de sensibilización y búsqueda de apoyo de organismos nacionales e internacionales a la

26. Parra Cortés, "Relaciones entre el arte y el derecho: ejemplos del arte en los procesos de protesta, memoria y reparación", 246.

27. Ávila Santamaría, La utopía del oprimido, 363.

28. Ibíd., 73. 
causa". ${ }^{29}$ El ojo que llora es hoy en día un atractivo turístico que en el fondo permite rememorar cada una de las voces que se encuentran talladas en él, en eso consiste el arte como instrumento de transformación.

La reparación inmaterial vista desde un enfoque de diálogo simétrico, dejaría de lado las relaciones asimétricas que se basan en la dominación del otro. El diálogo simétrico "sería la forma de saber que aprendiese a escuchar al ente en forma horizontal y simétrica" ${ }^{30}$ lo cual enriquece a la reparación inmaterial, dotándola de los requerimientos propios de las víctimas, para luego convertirse en un memorial, en un documental audiovisual, en mural, en pintura y demás manifestaciones artísticas que contemplan la voluntad de las víctimas, en virtud del diálogo horizontal con ellas. Convertir el diálogo asimétrico que despoja a la víctima y se apropia del conflicto en un diálogo simétrico horizontal donde víctimas y artistas participen activamente, es posible mediante el arte.

Por otro lado, enfocándonos en las manifestaciones artísticas, es indispensable debatir acerca del rol protagónico del artista que construya con sus habilidades la obra de arte reparadora. El efecto transformador debe encontrarse en las manos de quien esculpe la obra, pues "supone un artista comprometido con las reivindicaciones sociales, crítico de los sistemas de poder, dispuesto a romper hegemonías, y de otra parte, requiere de un receptor creativo, partícipe, coadyuvante de las mismas luchas". ${ }^{31} \mathrm{En}$ el caso de El ojo que llora, como se ha reiterado, el Estado incumplió su obligación de crear un monumento memorial a las víctimas e incluso su negativa es expresa al considerar que el monumento construido por Lika Mutal es suficiente.

Esa empatía en la lucha es necesaria para encaminar el arte hacia la transformación, pues el resultado siempre abarcará la vivencia y experiencia de quienes sufrieron la violencia desatada por el poder y sus ideologías. Allí radica también la transformación, pues como señala Walter Benjamin: "La unicidad de la obra de arte se identifica con su ensamblamiento en el contexto de la tradición. Esa tradición es desde luego algo muy vivo, algo extraordinariamente cambiante", ${ }^{32}$ lo que implica que la obra de arte refleja la unidad entre decisión judicial, víctimas, artistas y el propio Estado.

Por último, el fin de la transformación es modificar los condicionamientos de vulnerabilidad que permiten la perpetración de violaciones a los derechos humanos. El principal condicionamiento que genera vulnerabilidad se encuentra en el poder estruc-

29. Sierra León, "Relaciones entre el arte y los derechos humanos", 96.

30. Eugenio Raúl Zaffaroni, Crímenes de masa (Buenos Aires: Ediciones Madres de Plaza de Mayo, 2012 ), 56.

31. Sierra León, "Relaciones entre el arte y los derechos humanos", 93.

32. Walter Benjamin, "La obra de arte en la época de su reproductibilidad técnica", 1989, 5, 〈https://www. ucm.es/data/cont/docs/241-2015-06-06-Textos\%20Pardo_Benjamin_La\%20obra\%20de\%20arte.pdf . 
turalmente discriminante que se compone del "patriarcado, junto con la confiscación de las víctimas y el establecimiento de la verdad por interrogación violenta". ${ }^{33}$ Estas son las tres vigas maestras que generan vulnerabilidad en la población a sufrir los efectos tanto de atentados a los derechos humanos como sus violaciones sistemáticas. La táctica de la confiscación de la víctima puede revertirse a través del diálogo simétrico, que confiere voz a las personas que sufren esas violaciones, cuestión que se consigue a través del arte y de la concepción del derecho desde una perspectiva integradora que comprometa seriamente las demandas de las víctimas.

Como se ha venido argumentando, los artistas y las víctimas en las decisiones judiciales son de gran relevancia, pues una reparación inmaterial o simbólica se expresa en el arte, pero para su construcción es necesaria la voz de quienes se intenta reparar. La Corte IDH irrespetó esta premisa, pues no consideró la voluntad de las víctimas en su integralidad. Luego, despojó de las vivencias propias a las víctimas en el caso de La Cantuta, al disponer su inclusión en El ojo que llora, sin considerar que el Estado había incumplido su obligación de erigir un monumento a su costa y bajo su responsabilidad en el caso precedente de Barrios Altos.

Asimismo, en el caso Penal Castro Castro irrespetó la memoria de las víctimas y los deudos, al intentar incorporar los nombres de los muertos del penal en una escultura que contenía un sentido y un significado diferente al que originó las muertes en el establecimiento penal, lo cual originó problemas políticos y sociales, tanto así que los familiares de las víctimas cuyos nombres descansaban en el monumento El ojo que llora, se opusieron vehementemente a incorporar los nombres de los asesinados en el Penal Castro Castro, pues para ellos fueron terroristas que originaron la guerra en su país.

Para evitar estos inconvenientes, es necesario que la Corte IDH conciba a la reparación inmaterial como un instrumento transformador, que es posible a través del arte. Los condicionamientos de la vulnerabilidad tienen relación con la discriminación de las víctimas que sufren los atentados a sus derechos. Por esta razón, la alternativa se encuentra en un deber ser del derecho comprometido con el ser del arte, construyendo una lucha que se refleje en las obras artísticas. Para culminar, recordemos una máxima de Heidegger: "El modo en que el hombre vive el arte es el que debe informarnos sobre su esencia". ${ }^{34}$

33. Eugenio Raúl Zaffaroni, "El discurso feminista y el poder punitivo", en Las trampas del poder punitivo. El género del derecho penal, ed. Haydée Birgin (Buenos Aires: Biblios, 2000), 19, «http://www.biblio.dpp. cl/biblio/DataFiles/14202.pdf .

34. Martin Heidegger, Caminos de bosque (Madrid: Alianza Editorial, 1995), 68. 


\section{CONCLUSIONES}

Una reparación inmaterial transformadora se basa en cuatro aspectos a considerar: 1. participación de las víctimas al determinar la forma de reparación, en consecuencia, no homogeneización, ni estandarización. 2. Equilibrio entre los elementos éticos y estéticos, y participación de las víctimas en el proceso de creación de la obra. 3 . Arte accesible. 4. Manejo, mantenimiento y conservación. Las decisiones de la Corte IDH sobre reparación inmaterial pueden optimizarse a través de estos estándares, entregando a las víctimas un espacio artístico en el cual puedan denunciar, rememorar, conservar y garantizar la no repetición de los hechos que generaron las violaciones de derechos humanos.

La decisión de la Corte IDH respecto de reparación inmaterial en el caso Barrios Altos vs. Perú omite varios de los estándares, como la activa participación de las víctimas al momento de determinar la forma en que piensan y sienten la obra artística. La Corte IDH tampoco consideró los elementos éticos y estéticos del monumento a erigir. Otro error de la Corte IDH radica en pasar por alto que la obra debe construirse en un lugar accesible, esto con el fin de que el gran auditorio social pueda concurrir a fin de fomentar conciencia colectiva. De igual modo, la Corte IDH no se preocupó por fijar los tiempos y formas para el manejo, mantenimiento y conservación del monumento conmemorativo, es decir, convertir al monumento en una reparación que no se agota. Como resultado de estas omisiones, el Estado al no encontrar establecidas las condiciones en las que debe construirse el memorial, ha incumplido con su obligación excusándose en que ya existe una obra destinada a la reparación, El ojo que llora.

El Estado no cumple con la garantía de no repetición para las víctimas, pues sin un monumento en el que concurra la participación activa víctimas-artistas-Estado es impensable fomentar conciencia para prevenir que las violaciones a los derechos humanos no vuelvan a ocurrir. En este sentido, la sentencia no logra entregar una reparación inmaterial que sumerja activamente a las víctimas, al artista y al Estado, lo cual es fundamental para conseguir una reparación simbólica integral.

El punto clave para conseguir una reparación inmaterial eficaz se encuentra en que las manifestaciones artísticas deben elaborarse por artistas comprometidos con la causa, pues la dialéctica del arte implica un proceso transformador que abarque a víctimas, artistas y al Estado obligado a reparar. En el caso de la sentencia Barrios Altos, la Corte IDH y el Estado inobservaron estas condiciones que deben plasmarse en la obra de arte, pues ninguno entregó una adecuada reparación inmaterial.

Las sentencias de la Corte IDH deben adecuar a sus decisiones los estándares sobre reparación inmaterial aquí expuestos, con el fin de construir relaciones horizontales con las víctimas de violaciones de derechos humanos, lo cual se consigue otorgándoles poder de decisión, tanto en la forma y el fondo de lo que sus vivencias y expe- 
riencias determinen sobre el contenido de la manifestación artística. El arte que sirva como reparación a las víctimas debe necesariamente incluir la voz de los afectados, para convertirse en un instrumento de transformación.

\section{BIBLIOGRAFÍA}

Ávila Santamaría, Ramiro. La utopía del oprimido. Los derechos de la pachamama (naturaleza) y el sumak kawsay (buen vivir) en el pensamiento crítico, el derecho y la literatura. Ciudad de México: Akal, 2019.

Barthes, Ronald. Mitologías. Buenos Aires: Siglo XXI, 2008.

Benjamin, Walter. "La obra de arte en la época de su reproductibilidad técnica”. 1989. «https:// www.ucm.es/data/cont/docs/241-2015-06-06-Textos\%20Pardo_Benjamin_La\%20 obra\%20de\%20arte.pdf>.

—. La obra de arte en su reproductibilidad técnica. Ciudad de México: Ítaca, 2003.

Corte Interamericana de Derechos Humanos. "Resolución de supervisión de cumplimiento". Caso Barrios Altos y Caso la Cantuta vs. Perú. 30 de mayo de 2018.

-. "Sentencia de fondo, reparaciones y costas". Caso del Penal Miguel Castro Castro vs. Perú. 25 de noviembre de 2006.

—. "Sentencia de fondo, reparaciones y costas". Caso La Cantuta vs. Perú. 29 de noviembre de 2006.

—. "Sentencia de fondo". Caso Barrios Altos vs. Perú. 14 de marzo de 2001.

—. "Sentencia de reparaciones y costas". Caso Barrios Altos vs. Perú. 30 de noviembre de 2001.

—. "Resolución de supervisión de cumplimiento". Caso Barrios Altos vs. Perú. 7 de septiembre de 2012.

Guglielmucci, Ana. "El concepto de víctima en el campo de los derechos humanos: una reflexión crítica a partir de su aplicación en Argentina y Colombia". Revista de Estudios Sociales, n. 59 (2017): 83-97. 〈http://www.redalyc.org/pdf/815/81549422008.pdf〉.

Heidegger, Martin. Caminos de bosque. Madrid: Alianza Editorial, 1995.

López Medina, Diego Eduardo. El derecho de los jueces. Bogotá: Legis Editores, 2008.

Parra Cortés, Lina Victoria. "Relaciones entre el arte y el derecho: ejemplos del arte en los procesos de protesta, memoria y reparación". Anamorphosis-Revista Internacional de Direito e Literatura 5, n. ${ }^{\circ}$ (2019): 235-52. «http://seer.rdl.org.br/index.php/anamps/article/ view/468/pdf>.

Sierra León, Yolanda. "Relaciones entre el arte y los derechos humanos". Revista Derecho del Estado, n. ${ }^{\circ} 32$ (2014): 77-100. 〈https://revistas.uexternado.edu.co/index.php/derest/article/ view/3815>.

Vargas Llosa, Mario. “El ojo que llora”. El País, 2019. «https://elpais.com/diario/2007/01/14/ opinion/1168729205_850215.html>. 
Villabella, Carlos Manuel. "Los métodos en la investigación jurídica. Algunas precisiones”. En Metodologías: enseñanza e investigación jurídicas, editado por Wendy Aide Godínez Méndez y José Heriberto García Peña, 921-53. Ciudad de México: UNAM / Tecnológico de Monterrey, 2015. 〈https://archivos.juridicas.unam.mx/www/bjv/libros/8/3983/46.pdf〉.

Zaffaroni, Eugenio Raúl. Crímenes de masa. Buenos Aires: Ediciones Madres de Plaza de Mayo, 2012.

—. "El discurso feminista y el poder punitivo". En Las trampas del poder punitivo. El género del derecho penal, editado por Haydée Birgin, 19-30. Buenos Aires: Biblios, 2000. 〈http:// www.biblio.dpp.cl/biblio/DataFiles/14202.pdf). 